\title{
Evolution of personal protective equipment from its inception to COVID-19
}

\author{
P. L. Jagadeshvaran, Aishwarya Vijayan Menon and Suryasarathi Bose* \\ Department of Materials Engineering, Indian Institute of Science, Bengaluru 560 012, India
}

\begin{abstract}
A bizarre illness, identified in a group of patients with respiratory problems in Wuhan, China; was then ascertained as the coronavirus disease 2019 (COVID19) - that proliferated into a global pandemic, with lakhs of people getting infected per day. Given this pandemic situation, there is a need globally for the use of personal protective equipment (PPE) to protect oneself from getting infected by the disease. This is very much critical in the healthcare sector as healthcare units like hospitals and clinics might act as potential epicentres for the spread of a disease and cause the healthcare workers to act as vehicles for disease transmission. Given this context, this review article primely focuses on the different ways to prevent transmission of virus and the different PPE that exist in the market. The various anti-viral technologies which are currently available in the market to tackle SARS-CoV-2 have been described along with few interesting literature which can be looked upon to develop anti-viral PPE that can be effective against enveloped viruses like the current SARS-CoV-2.
\end{abstract}

Keywords: Antiviral technologies, COVID-19, healthcare workers, nosocomial infections.

WE are living in a time when a viral disease has put a halt to our normal life. The disease has been named after its causative agent, the severe acute respiratory syndrome coronavirus 2 (SARS-CoV-2), as coronavirus disease 2019 (COVID-19). SARS-CoV-2 manifests as dry cough, frequent fevers and in severe cases pneumonia, putting the population above 75 years of age, and those with immunodeficiency or chronic and oncological diseases under severe risk. However, the category that is most exposed to the virus is that of hospital personnel ${ }^{1}$. In the current scenario when there is no concrete information about the fate of the present vaccines for treatments, it is imperative to ensure the protection of health-care workers (HCWs) to prevent virus transmission and guarantee continuous patient care. Therefore, it is important to provide them with proper personal protective equipment (PPE).

PPE refers to the ensemble of protective apparels like clothing, masks, helmets, goggles and others that are designed to safeguard the wearer's body from injury or

*For correspondence. (e-mail: sbose@iisc.ac.in) spread of infection - mostly used to maintain occupational safety. In the healthcare context, PPE are predominantly used by HCWs to contain the transmission of diseasecausing agents from bodily fluids or a harmful environment, thereby forming a barrier during treatment. PPE are also used to protect patients who are at a high risk of contracting infections. PPE not only protect $\mathrm{HCW}$, but also stop the transfer of microorganisms by protecting their various entry ports (skin, airway and mucous membrane) from direct contact. During an infection outbreak, PPE are of critical need by the healthcare community who are highly vulnerable to the spread of the disease. When utilized in the right way with other infection-control practices, PPE prove to be effective in minimizing the spread of disease ${ }^{2}$.

Despite the proper usage of PPE, HCWs continued to contract the coronavirus. One of the major reasons for this was the contamination of PPE in hospitals. Recently, it has been reported that SARS-CoV-2 has a lifespan of about 2-3 days on plastic and textile surfaces ${ }^{3}$. This puts the wearers of PPE at high risk, since most of them are made of either textile or plastic materials. This finding is consistent with previous reports regarding the survival of human coronavirus 229E, SARS coronavirus and influenza A (H1N1), and shows that enveloped viruses like the current SARS-CoV-2 can survive for several hours on PPE like gloves and fabric. It has been reported that the infectious viruses can survive on PPE for the length of a patient care encounter, which can cause transfer of virus when the PPE is handled after wearing. The transfer of viruses from fabric and gloves to hands during the removal of contaminated PPE has also been demonstrated in the literature ${ }^{4}$. Another major factor is the disposal of the used PPE which not only increases the chances of virus transmission but also causes an environmental problem of disposal of plastics. Not to mention the shortage in supply of PPE due to their non-reusability and high demand.

To tackle the issues of disposal as well as supply shortage, PPE are being disinfected to make them safe for reuse. Several strategies have been considered in this regard to improve the reusability of PPE. Some of these include use of disinfectants such as vaporized hydrogen peroxide (VHP), ultraviolet (UV) light exposure and ethanol decontamination strategies. However, all of these strategies severely impact the repeated usability of PPE. 
Fit test data showed functional degradation by both ethanol and UV decontamination routes to different degrees. However, VHP-treated masks showed no significant change in PPE function until two treatments ${ }^{5}$.

If the PPE themselves have inherent viricidal properties, they can be used for prolonged periods without the need for additional disinfection treatments. Moreover, this also prevents the transmission of viruses through PPE during patient care and handling ${ }^{5}$. The PPE which are generally textile/plastic-based can be made antiviral either by incorporating antiviral agents during the textile fibre manufacture or they can be applied as a textile finishing or coating by spray/dip-coating in the final stages. The coating has the potential to reduce the risk of secondary infection by limiting the transmission of microbes. This will allow reusability of PPE and easy containment of microbes. It will also lead to less burden on the manufacturers for making millions of masks, which are generally discarded after a single use. It can also restrict the spread of microbes to fingers and to other individuals due to negligent usage of masks where users tend to touch them while removing. It also reduces bioburden and transmission after disposal. This is neither the first nor the last pandemic that the world is going to experience. Hence it is of importance that we come up with technological solutions to challenge the ongoing and future global health emergencies ${ }^{6}$.

This comprehensive article illustrates the critical need to use PPE by outlining the various ways in which infections can be transmitted in a healthcare set-up and the basic principles of epidemiology to understand the chain of infection. The technologies and materials used in different PPE (like masks/respirators, gloves and gowns) and the different selection criteria to use a particular PPE are discussed elaborately to enable the readers to judiciously select them for use. The various antiviral technologies which are currently available in the market (already in use or can be potentially used to develop antiviral PPE) to tackle the current SARS-CoV-2 are described. This article discusses studies that can be a referral to developing antiviral PPE that can be effective against enveloped viruses like SARS-CoV-2.

\section{Infection-transfer mechanisms associated with healthcare}

Healthcare environments like hospitals and testing laboratories are multifaceted organizations with several connecting links. There also exists an intricate interplay between the HCWs, patients and microorganisms. This also sheds light on the fact that patients admitted to healthcare institutions are more vulnerable to be affected by an infection than their counterparts in a given population under study. This is due to the fact that patients with infections come in contact with susceptible patients and are generally looked after by the same staff. There are typically several models that explain the interactions between the source, host and microorganisms present in a healthcare environment. This highlights that hospitalacquired infections, also called nosocomial infections, play a significant role during an infection outbreak and must be prevented by suitable means ${ }^{7}$.

Nosocomial infections are, in most cases, unforeseen and progress over the course of treatment, resulting in severe complications. These require subsidiary therapeutic and diagnostic intervention, leading to prolonged stays at hospitals and adding to the cost of treatment. Such infections may be opportunistic in some cases, where a patient's existing infection would lead to several other complications. In most cases, the source of infection is external-either inanimate that the patient comes into contact within a hospital, or the hospital environment itself comprising other patients and HCWs. Any diseasecausing pathogen must be transferred from a reservoir to an appropriate location on the surface of a vulnerable host in adequate quantities to multiply and cause an infection. In such a scenario, 'breaking the chain' at the mode of transmission is highly critical to disrupt the spread of any infection, thereby enabling its prevention and control to be successful. Microorganisms are mainly transmitted via four routes in healthcare set-ups, viz. contact, droplets, airborne and vehicles.

(i) Contact: This is the most common and frequent form of transmission. It takes place in two ways: direct and indirect. Direct contact occurs when the pathogen is transferred from the reservoir to a vulnerable individual without the involvement of any other elements. For instance, body-to-body surface contact (like touch), which involves physical transfer of the pathogen from the infected person. Indirect contact encompasses a wide spectrum of cases, where a vulnerable host is in contact with the pathogen through an intermediary which might be inanimate (surfaces, clothing and fomites) or animate (a HCW who may be in contact with an infected patient). Pathogens transmitted by this way include Klebsiella spp., Staphylococcus aureus, Acinetobacter spp., Clostridium difficile, rotavirus, noroviruses, respiratory syncytial virus and enterobacteria that are Gram-negative bacilli and show antimicrobial drug resistance.

(ii) Respiratory droplets: Transmission can occur through droplets of around $20 \mu \mathrm{m}$ emanating from a patient. These droplets, generated during sneezing, coughing and talking, contain pathogens that are propelled into the air. When these pathogens land on a new host, they enter the body predominantly through the mouth, conjunctivae and nasal mucosa. Stability of these droplets is primarily dependent on their size. Droplets are typically around $20 \mu \mathrm{m}$ or less in size, and do not stay suspended in the air for a long time, travelling distances less than a metre. 
However, the droplets may possibly linger on surfaces in the vicinity and remain active for longer periods, thereby making cleaning of surfaces mandatory. Influenza, whooping cough, meningococcal meningitis, respiratory syncytial virus, cold, diphtheria, pneumonia, adenovirus and coronaviruses (SARS CoV, SARS CoV-2 and Middle East respiratory syndrome) represent a few infections that are transmitted this way.

(iii) Airborne spread: Here transmission takes place through air as the medium. Air contains infectious droplets (as mentioned above) and dust particles being covered with/containing infectious microorganisms. Due to air currents, such particulates stay disseminated in the environment for longer time periods and spread over a wide area (hence travel distances larger than those travelled by droplets). This way of transmission is dangerous, as airborne nuclei can reach the alveoli (lungs) of the host system when they are inhaled, even when there is no direct contact with the patient. Droplets are generated by several clinical procedures like respiratory kinesiotherapy, fogging, fibre-optic bronchoscopy, airway aspiration, sputum induction, tracheal intubation, centrifugation of samples and non-invasive positive pressure ventilation, apart from coughing, sneezing and talking. SARS-CoV transmission studies state that clinical procedures like tracheotomy, tracheal intubation, non-invasive and manual ventilation reportedly pose high risks for transmission. Few examples of pathogens transmitted through this route include rubeola, Mycobacterium tuberculosis, hantaviruses, varicella, chickenpox and measles.

(iv) Common vehicles: Here transmission occurs by common objects and contaminated instruments used by more than one patient. Clinical apparatus when used without proper disinfection may act as a vehicle transferring the microorganisms into a new host. Also, this is valid only when multiple people get exposed to and develop illness from a common inanimate object. Common vehicles do not facilitate the replication of viral DNA, while bacterial cells can multiply ${ }^{8}$.

A thorough knowledge of the transmission mechanisms of infections is vital to develop PPE for healthcare applications.

\section{Textile-based PPE}

\section{Masks and respirators}

Masks and respirators are the first protection for HCWs in a potentially infectious (mostly airborne) environment. Though present-day hospitals are well-equipped with negative pressure ventilation, disinfection, air filtration and isolation wards, they do not offer adequate protection to HCWs from airborne droplets - thereby making respiratory protection necessary. The overall effectiveness of such equipment is dependent on factors like: (i) fit characteristics of the respirator model, (ii) level of protection required, (iii) care to be taken during the use of such respirators and (iv) the adequacy of training and quality control $^{9}$.

Masks were put to use at the beginning of the 20th century to prevent contamination to open surgical wounds. The first ones to be used were reusable and fabricated with multiple layers of cotton gauze. The multilayer architecture yielded high protection efficiency, but the heavy masks failed to provide a good level of comfort to the wearers (mainly HCWs). Five decades down the line, non-woven mats made of fine glass fibre were used for making disposable masks because of their lightweight. By the end of the 20th century, masks were made of different fibres like cellulose and polypropylene. The protection efficiency of a mask depends upon the material used, with polypropylene, polyester-rayon, glass and cellulose, in descending order, showing a decreasing trend in terms of protection efficiency. The use of glass fibre to make masks has been drastically reduced because of the irritation and potential damage caused by their use. Polypropylene is identified as one of the best fits here because of its hydrophobic nature and wicking capacity that enables a comfortable and dry microclimate between the face and the mask ${ }^{10,11}$.

Modern-day surgical masks are made of non-woven fabrics with enhanced bacterial filtration and air permeability, and also being less slippery than normal cloth. Contemporary market mainly uses polypropylene to make non-woven mats intended to be used for masks, while other materials like polystyrene, polyester, polycarbonate and polyethylene are also used for the same ${ }^{12}$. Surgical masks are three-ply made by sandwiching a textile layer with bonded non-woven fibre mats on both sides (Figure 1). They often constitute two filter layers enabling the

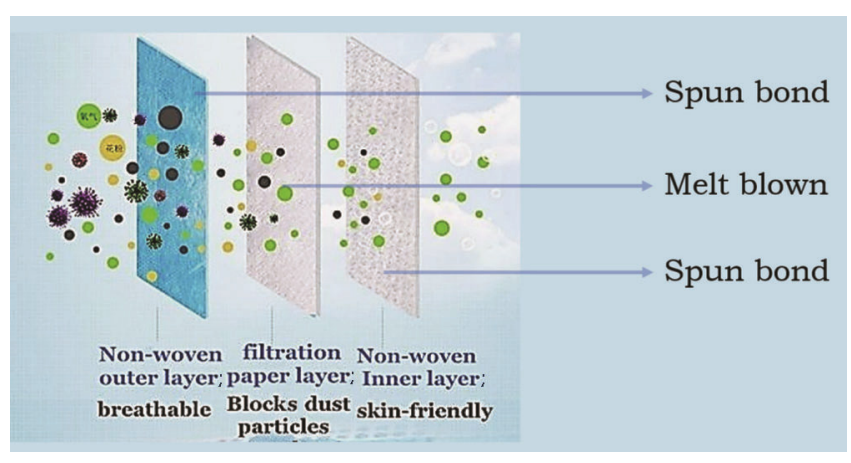

Figure 1. Schematic of different layers used in a surgical mask (credits: VOVA). 


\section{REVIEW ARTICLES}

filtration of bacteria of around $1 \mu \mathrm{m}$ size. Filtration efficiency of a mask is usually a function of the material used in making the fibre, its cross-section, the manufacturing method involved and the web structure.

Though contemporary multilayered masks efficiently filter larger microorganisms, and airborne droplets like those released from coughing and sneezing, they are not effective in filtering sub-micron sized particles. Also, there is air leakage from the edges of the mask through which fine droplets can easily pass, as the masks do not tightly fit the face. Consequently, masks do not completely impede the proliferation of infection in case the HCWs during a pandemic situation like COVID-19. As a result, there is a strong need for respiratory protection devices having higher protection efficiency and better fit to face in order minimize leakage.

Respirators were put into use to overcome the shortcomings of surgical masks. Initially, it was the protection of miners from hazardous gases and dust, and soldiers from chemical warfare that gave the impetus for the development of respirators in the early 1900 s. With the increase in risk of drug-resistant tuberculosis, respirators were used by HCWs in the 1990s. The outbreak of SARS and its impact on the HCWs helped throw more light on the use of respirators during such conditions ${ }^{13}$.

The performance of respirators is assessed using two important parameters: (i) ability to capture particles of various sizes (typically $<1$ to $>100 \mu \mathrm{m}$ ) over a range of airflow (10 to $100 \mathrm{l} / \mathrm{min}$ ), and (ii) design to prevent leakage of air at the face-face piece boundary ${ }^{14}$.

A respirator typically comprises multiple layers of nonwoven fabric, usually of polypropylene. The two protective layers (covering the inside and outside of the mask) are fabricated by spun bonding - where nozzles blows molten threads of a thermoplastic polymer to layered threads of size ranging between 15 and $35 \mu \mathrm{m}$ onto a conveyor belt, that is made into a cloth by the continued movement of the belt. Fibres produced this way are bonded by mechanical, thermal or chemical techniques. The layers prepared by this process usually have a surface density between 20 and 50 GSM and confer protection from the outside environment besides acting as a barrier to the particles and droplets that are exhaled by the wearer. The pre-filtration and filtration layers constitute the inner layer. The pre-filtration layer is needled and non-woven (needle punched to enhance cohesiveness), subjected to hot calendering to make it thicker and stiffer (surface density of around 250 GSM), thus giving it the desired shape and fit. The last and important layer is a high-efficiency, melt-blown, electret (i.e. polarized), nonwoven material which controls the filtration efficiency. Melt-blowing is a process similar to spun bonding, where multiple nozzles spray threads (of size less than $1 \mu \mathrm{m}$ ) of a polymer melt using air on a conveyor - similarly leading to a fabric by the complete rotation of the conveyor. Full respirators are made by ultrasonic welding using converting machinery, by adding metal strips and straps which provide a fit over the wearer's nose.

Respirators must meet stringent certification tests established by NIOSH (National Institute for Occupational Safety and Health), USA, which uses the worstcase conditions for testing. Further, the standards and classifications of respirators are developed by NIOSH, which categorizes them based on their filtration efficiency. Respirators are usually rated based on their ability to collect a bare minimum quantity of the challenge aerosol. For instance, ratings of 95 and 99 are given to respirators which collect $95 \%$ and $99 \%$ of the challenge aerosols respectively, whereas a rating of 100 is given to those collecting $99.97 \%$ of the aerosols. Resistance to oil is critical for respirators, as some industrial oils can remove the electrostatic charge which reduces the filter performance. Respirators are given a ' $\mathrm{N}$ ' rating when they are not resistant to oil, ' $R$ ' if they are somewhat resistant to oil and ' $\mathrm{P}$ ' if they are strongly resistant (oil-proof). This totally gives nine types of particulate respirators (nine combinations of alphanumerical codes). HCWs commonly use N95 respirators as they are inexpensive, disposable and user-friendly ${ }^{15}$. Table 1 elucidates the differences between surgical masks and respirators ${ }^{16-18}$.

Though both respirators and masks have different degrees of filtration efficiency based on their ratings, there is no possibility of completely eliminating the spread of infection due to exposure to airborne infective droplets. This is because, the state-of-the-art respirators would not suffice to combat emerging pandemics like SARS-COV-2, unless combined with other devices like face shields. Another reason is that prolonged usage of masks and respirators in an environment with higher concentration of aerosols causes a decline in their performance. This poses a risk of secondary infection when the filter gets contaminated with pathogenic virions (of size $<100 \mathrm{~nm}$ ), in addition to mechanical handling.

\section{Gloves}

Gloves constitute one of the main components of PPE intended to prevent contact of the hands with any object causing potential infection - by acting as an impermeable barrier. In the healthcare context, gloves are used in several circumstances by HCWs to avoid infection on contact with a patient. There are two kinds of gloves used in healthcare: (i) surgical gloves and (ii) examination gloves. Surgical gloves are used in surgical procedures, and are hence manufactured with high precision and quality with requirements of sterility. These gloves are handspecific, harmless, odourless, soft and fit perfectly well to offer good protection to the surgeons. Examination gloves are used for non-invasive physical examination to prevent cross-contamination between caregivers and patients. These are usually non-sterile, inexpensive and intended for single use ${ }^{19,20}$. 
Table 1. Differences between a surgical mask and a respirator ${ }^{16-18}$

\begin{tabular}{ll}
\hline Surgical mask & \multicolumn{1}{c}{ Respirator } \\
\hline Barrier to splashes, droplets, exposure of biological fluids and spit. & $\begin{array}{l}\text { Prevents the wearer from inhaling aerosols or other droplets } \\
\text { (only non-oil aerosols). } \\
\text { Tested in the direction of inhalation (from outside to inside). } \\
\begin{array}{l}\text { Tested in the direction of exhalation (from inside to outside). } \\
\text { Effectiveness is accounted in terms of bacterial filtration. }\end{array}\end{array}$ \\
$\begin{array}{l}\text { Eoes not provide reliable level of protection from inhaling smaller } \\
\text { particles. }\end{array}$ & Filters out at least 95\% of particles during inhalation. \\
$\begin{array}{l}\text { Not designed to seal tight against the face. } \\
\text { Tested and approved for use by the FDA, USA. }\end{array}$ & $\begin{array}{l}\text { Designed to seal tight against the face. } \\
\text { Can be reused if not contaminated. } \\
\text { Tested and approved for use by NIOSH, USA. }\end{array}$
\end{tabular}

In order to ensure the efficient use of gloves to prevent infection transfer, it is necessary that they meet a few criteria which need to be considered while selecting them. These are sterility requirements (for surgical gloves, sterility is mandatory), permeability (ideally gloves must be impermeable), raw materials used and their durability, risk of inflammatory reactions (hypoallergenic), size, procedure-related requirements, compatibility with existing products, level of protection, comfort and fit, and overall quality versus cost ${ }^{21}$.

The first recorded use of gloves in healthcare applications was in 1890 at the Johns Hopkins Hospital, USA when the chief nurse suffered inflammatory reactions to mercuric chloride used for asepsis then ${ }^{22}$. Later, when the need for gloves in healthcare became apparent, sterilized latex gloves were in use for a short span of time. The production of disposable surgical gloves began in 1964, which was based on a process similar to making condoms $^{23}$

First-generation gloves (those made of latex) used lubricants to facilitate their donning - club moss or pines used initially proved to be toxic. Later, talcum powder and corn starch were employed, however, they were associated with complications like postoperative granuloma and scar formation ${ }^{24}$. The use of lycopodium powder had problems of skin irritation and impeded healing. Nonpowdered gloves were easy to don; however, a ban order on their use by FDA, USA, completely eliminated them from medical applications ${ }^{25}$. Yet another issue with powdered gloves was that their use in highly clean and sensitive environments like cleanrooms was difficult. Chlorination of latex gloves made it easy for them to be donned without the use of powders for lubrication - by reducing the surface friction and tack. Also, there was significant reduction in the quantity of allergenic latex proteins that cause allergy to the wearer. Yet, they suffered problems like loss of colour, chlorine odour and shorter shelf-life - as chlorination made the latex brittle. Non-chlorinated gloves on the contrary have none of these problems but are difficult to don and are unclean when it comes to the particles. This is due to the use of a polymer coat (a thin layer of gel or silicone), making them easier to don ${ }^{26}$.
Despite being an excellent choice for sensitive applications like surgery because of their flexibility and comfort, latex gloves showed poor resistance to chemicals (especially organic solvents)and were reported to cause allergy and skin irritation (due to allergenic proteins) $)^{27,28}$. Moreover, their poor puncture resistance made it difficult to identify laceration or holes (if any) in them - posing a threat to their superior dexterity ${ }^{29,30}$. To combat these problems, the use of non-latex gloves in surgical procedures and applications was encouraged.

Latex-free gloves have conveniently replaced latex gloves in less critical areas like basic patient care. There is only minimal documentation regarding their performance analysis in terms of barrier properties, tear resistance, etc. Synthetic polyisoprene gloves (synthetic form of latex) are the only latex-free gloves which are at par with latex gloves and still remain hypoallergenic. However, they are the most expensive substitute available for latex which did not favour their use extensively. Costeffective alternatives like vinyl gloves which are usually the cheapest substitutes for latex tend to have poor chemical and tear resistance. They have a longer shelf life; and are used in applications where dexterity is not critical. Nitrile gloves are also considered as potential alternatives to latex-free gloves, though their cost is roughly twice that of latex gloves. Yet, they are superior to latex gloves in terms of shelf life, tear resistance, chemical and oil resistance, temperature tolerance and ability to dissipate electrostatic charges. Further, they have less particles and hence can be used in sensitive applications like clean rooms. Though their tear resistance is high, they tear completely once the glove gets punctured-ensuring a replacement to protect hands. Figure 2 shows the different gloves explained above, while Table 2 provides a comparison of different gloves available in the market with their pros and cons ${ }^{31-33}$.

Quality of non-latex gloves depends on the raw material used, glove manufacturer and the stress to be experienced during clinical use. Selection of a particular pair of gloves for an application must be done keeping in mind the safety requisites of the workplace, after assessing the different risks involved. Neoprene gloves are emerging as promising substitutes to latex among the 
Table 2. Comparison of different disposable gloves sold in the market ${ }^{31-33}$

\begin{tabular}{|c|c|c|c|c|}
\hline Gloves & Raw material used & Advantages & Disadvantages & Protection level \\
\hline Latex & Natural rubber & $\begin{array}{l}\text { Excellent barrier performance, } \\
\text { biodegradable, flexible and } \\
\text { comfortable }\end{array}$ & $\begin{array}{l}\text { Allergic reactions, poor chemical } \\
\text { resistance }\end{array}$ & Bacteria, viruses \\
\hline Nitrile & Nitrile rubber & $\begin{array}{l}\text { Excellent chemical resistance, } \\
\text { durability and puncture resistance }\end{array}$ & Less tactile sensitivity, expensive & Chemicals, viruses \\
\hline Vinyl & Poly(vinyl chloride) & Inexpensive, longer shelf life & $\begin{array}{l}\text { Poor resistance to solvents, limited } \\
\text { dexterity and poor durability }\end{array}$ & Chemicals \\
\hline
\end{tabular}
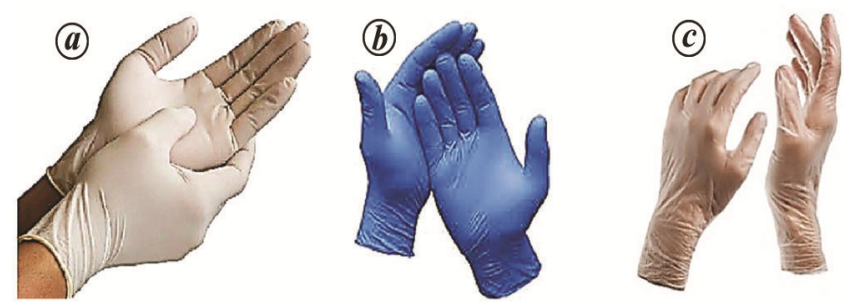

Figure 2. Gloves: (a) latex, (b) nitrile and (c) vinyl.

different latex-free gloves as they are considered safe to allergy, while nitrile gloves are considered to be rigid and poorly rated.

There exists a practice called double gloving, whereby two gloves are worn one on top of the other to maximize protection, which is justified because of the perforations in surgical gloves. Other reasons for double gloving include the risk of glove damage due to the use of sharp surgical instruments and reduction in danger of infection from glove failure. Also, studies show that most of the perforations in surgical gloves are unnoticed ${ }^{34}$. Though undetectable to the human eye, micro-perforations are sufficient to allow the passage of pathogens and such micro-perforations tend to increase with the duration of use $^{35}$. Studies show that double gloving considerably enhances protection against inner glove perforation by $71 \%$, in comparison to the use of a single pair of gloves ${ }^{36}$. In a study where ten nurses/surgeons were involved in 100 operations, 172 single pair of gloves sustained perforations, while only 50 inner gloves sustained perforations with double gloving - which shows considerable, viz. reduction $^{37}$.

Present-day research in gloves is based on the development of cost-effective substitutes for latex with effective barrier protection. Constant upgradation of hospital set-ups and the safety of HCWs lay down the basis for research on gloves. There is also a strong need to foster novel processes for making gloves with antimicrobial properties. In the future gloves may be envisaged as puncture-free materials with superior tear resistance, with capabilities to handle sharp instruments ${ }^{38}$. All these challenges will drive the market towards the development of non-latex materials.

\section{Gowns}

Human skin and mucous membranes are potential media for the transfer of pathogens to cause a disease, which can be inhibited by an impermeable barrier having pore size less than the size of the pathogens. Gowns have been used in healthcare set-ups to prevent the dissemination of infection by limiting or expelling infectious agents and reservoirs, disrupting the transmission cycle and safeguarding susceptible patients ${ }^{39}$. They are meant to cover the torso and clothing, which may be potential vehicles for the transfer of infection. Gowns are the second most used PPE after gloves in a healthcare set-up and are part of an overall infection control strategy.

Medical gowns are classified into three types by FDA based on the risks involved. (i) A surgical gown is worn by healthcare personnel during surgeries to prevent transfer of pathogens, body fluids and particulate matter. It is a class-II medical device as regulated by the FDA and can be used in any regulated risk level. (ii) A surgical isolation gown is used when there is relatively high risk and need for larger critical zones than the traditional surgical gowns. This is also a class-II medical device (with premarket review) as regulated by FDA. (iii) The nonsurgical gowns are used in minimal risk areas to protect the wearer and are class-I medical devices exempted from premarket review. These are not used during surgical procedures or when there is a relatively high risk of infection spread ${ }^{40}$.

Historically, the surgical gowns were used to protect patients from $\mathrm{HCWs}$, which required a relatively loose, breathable and comfortable fabric. The materials used for making such gowns were cotton and 50/50 cotton/ polyester blends. Liquid absorption and frequent washing (for reuse) caused deterioration in the fabric quality, though they were inexpensive ${ }^{41}$. Besides, increasing concerns about threats related to transmission of pathogens made surgical gowns indispensable for HCWs. This now makes clear the fact that a surgical gown must ideally be liquid-proof (impenetrable by any liquid) and breathable (providing a comfortable micro-climate between the user and the gown), besides protecting from microorganisms and particulate matter. Alongside, there must be a clear assessment of the healthcare set-up, which anticipates 
contact while providing care with potentially infectious objects or surfaces and the nature of interaction with patients ${ }^{42}$.

As seen above, the traditional materials used for making surgical gowns were cotton and cotton-polyester blend. There was a synergistic improvement in the properties of cotton-polyester blend - it was both breathable and strong ${ }^{43}$. However, the pore size was sufficiently large to allow passage of liquids, thereby not providing a barrier. Though there were attempts to make them hydrophobic (using fluoropolymer treatment) and reducing pore size (tight weaving of the fabric), subsequent washing led to deterioration of properties. Also, there was no concrete evidence about the antimicrobial properties of the fabric ${ }^{44}$. The generation gowns were made with fine filaments of polyester, weaving them in a dense fashion to gain barrier properties. Conductive carbon fibres were also used to incorporate antistatic properties. However, their properties were only retained by a liquid repellent coating in every reprocessing cycle. Present-day surgical gowns are designed in a multi-layered fashion (usually three-ply) in order to meet several objectives. The outermost layer confers mechanical durability in terms of abrasion and puncture resistance; the middle layer is highly impermeable offering excellent barrier properties, while the bottom layer is usually soft and mainly incorporated for comfort besides adding another layer of protection. Three-ply gowns were also made using a microporous membrane by sandwiching it between layers of polyester fabric. The membrane used is polyvinylidenefluoride (PVDF) which is mechanically stretched to build up resistance against tear and infiltration of viruses and fluids ${ }^{45}$.

Gowns are classified based on their usability as single use/disposable and multiuse/reusable. Single-use gowns are primarily made from non-wovens by the incorporation of additives to enhance liquid repellency. A variety of natural (like cotton) and synthetic (like polyester materials) are engineered by special bonding techniques and finishes to achieve the desired property profile. There is no deterioration in barrier properties and problems about reprocessing here, as the gowns are disposed after single use. In most cases, disposable gowns are offered presterile by the manufacturer and there is no need to separately sterilize them. Studies show that single-layer nonwovens failed to prevent bacterial transmission ${ }^{46}$, while multilayer nonwovens resisted transmission of bacteria ${ }^{47}$. Reusable gowns were made from cotton and its blend with polyester. Tightly woven polyester-cotton blend with fluoropolymer finish constitutes the first-generation reusable gowns. Composite fabrics made by laminating a combination of knitted or woven fabrics are the new surgical materials ${ }^{48}$. Lamination could be replaced by coating, nevertheless, both techniques confer resistance to liquid penetration. Reusable gowns offer a variety of advantages like reduction in clinical waste, cost-saving (washing cost of reusable gowns is relatively low compared to the use of disposable gowns ${ }^{49}$ ), and have less impact on the environment.

The design and engineering involved in medical gowns is critical as several criteria must be considered - to not compromise on the performance. The general requirements are as follows: (i) Gowns must allow sufficient freedom of movement besides providing a close fit, with no openings for breach of barrier. (ii) They must be breathable to provide ventilation (to dissipate the heat generated by the body) and comfort to the body, besides imposing a strong barrier to penetration of liquids and particulates. (iii) They must fit a variety of body sizes, be sterile, lint-free and provide easy donning and doffing without contamination. (iv) Gowns should not promote the proliferation of microorganisms on their surfaces leading to spread of secondary infections.

The use of surgical gowns has increased globally with an increase in the number of surgeries, which is a major thrust for research in the field of protective clothing. Another cause is the widespread awareness among the people about the spread of infections and safety measures. The use of disposable gowns is gaining more light in the medical world due to complications and threats of secondary infection associated with reusable gowns, besides their deterioration in properties during reprocessing. The use of disposable gowns is encouraged as reusable gowns restrict the sales of new products. The future of present-day medical gowns is heading towards smart surgical gowns leading to its increasing demand ${ }^{50}$.

\section{Currently available/soon to be available strategies to develop antiviral PPE against SARS-CoV-2/influenza}

Aqualyte, a non-toxic, biocidal polymer coating developed by Dias Analytic Corporation (Florida, USA) is a promising coating material that can be applied onto most surfaces, including PPE. It is a sulphonated block copolymer that can self-organize on solidification, forming a network of hydrophilic and hydrophobic regions within a dense polymer layer with a smooth, nonporous surface. Enveloped viruses like SARS-CoV-2 maintain an outer protective envelope composed of lipid bilayers and various proteins that help them survive outside the host cells during transmission, and also help enveloped viruses to hide from the host immune system. This envelope is vulnerable to desiccation and disruption in the presence of the highly polar sulphonic acid groups within the Aqualyte polymer ${ }^{51}$.

HeiQ Materials AG, Zurich, Switzerland, a supplier of finishing technology, has launched HeiQ Viroblock NPJ03, which is an antiviral and antimicrobial textile treatment that has been proven to be effective against SARS-CoV-2. The antiviral finish increases the antiviral 
performance of face masks significantly, such that when the untreated mask exhibits a 2.9 log antiviral reduction, the treated mask exhibits a 4.48 log antiviral reduction, which is a $99.99 \%$ reduction of virus infectivity (a log reduction of 2 is equivalent to 100 times the effectiveness). The textile finish consists of a unique combination of vesicles that target lipid-enveloped viruses like the coronavirus causing their deactivation, and silver technology which inhibits their replication. HeiQ Viroblock NPJ03 also demonstrates virus infectivity against various types influenza like H1N1, H5N1 and H7N9 (ref. 52).

Devan Chemicals, a textile innovator and speciality chemical producer in cooperation with the Institut Pasteur de Lille, France, has tested its liquid product BI-OME, which was found to have strong antiviral capabilities against enveloped viruses like SARS-CoV-2, H1N1, etc. as well as naked viruses like rotavirus. Using BI-OME on outdoor and work-wear could reduce the risk of virus proliferation and contamination ${ }^{53}$.

According to the literature, nanoparticles of zinc oxide, cuprous oxide, silver, copper (I) iodide and gold on silica nanoparticles $\left(\mathrm{Au}-\mathrm{SiO}_{2} \mathrm{NPs}\right)$ and also some quaternary ammonium cations (QUATs) are promising to inactivate various types of viruses. Nova Surface-Care Centre Pvt Ltd has developed a product called NANOVA HYGIENE + TM, which is an antimicrobial coating that can be applied on various surfaces, including fabrics, plastics, metals and concrete. It is a cocktail of nonmigratory QUATs and positively charged silver nanoparticles (AgNPs) which are dispersed in a polymeric binder. These coatings exhibit extremely low surface energy $(>20 \mathrm{mN} / \mathrm{m})$ and behave like an omniphobic surface by repelling both water and oil. Contact angles when measured against water and hexadecane were $>130^{\circ}$ and $>50^{\circ}$ respectively. The coatings have a proven antibacterial efficiency of up to $99.9 \%$, according to the global standard JIS Z2801. The coatings have the capability to repel and inactivate viruses, including SARS-CoV-2. They are also effective against fungi and algae pathogens. AgNPs show antiviral action by inhibiting the replication of virus nucleotide. AgNPs bind to electron-donor groups such as sulphur, oxygen, and nitrogen that are commonly found in enzymes within the microbes causing the enzymes to denature, and therefore effectively incapacitating the energy source. The cationic silver can inactivate SARS-CoV-2 by interacting with its spiked surface proteins $^{54}$.

NBC Meshtec, Japan, developed a technology called Cufitec $^{\circledR}$, which is an antiviral and anti-bacterial technology utilizing nanoparticles of a monovalent copper compound. These nanoparticles can be processed for use in a variety of materials and for a wide range of applications. They can be fixed to any textile fibre matrix; the fibre or film matrix can be coated with monovalent copper compound nanoparticles; the monovalent copper compound nanoparticles can be blended into synthetic plastic, and the monovalent copper compound nanoparticles can be mixed into alcohol or any other liquid ${ }^{55}$.

A team of researchers from the Hohenstein Institute in Bönnigheim, Germany, developed a textile finish based on copper pigments that could be applied on microfibre clothes, similar to dyeing with dispersion dyes. The incorporation of these copper pigments in textile microfibre clothes was done using different approaches. The dispersed copper pigments were incorporated into the textile fibres and bound with a polymer agent in a cold-padding process to protect copper from mechanical abrasion. In another approach, antiviral finish was achieved by finishing the copper pigments in a high-temperature exhaust process. The fabrics were found to be skin-friendly with a slight green hue. When the clothes were used to wipe glass, stainless steel and wood surfaces contaminated with polio, hepatitis A and other clinically relevant viruses, they absorbed $91 \%$ of the applied viruses and virus concentration was reduced by roughly $90 \%$ (ref. 56).

A team of researchers at Indian Institute of Technology Guwahati, have developed an affordable antiviral and antibacterial spray-based coating for PPE. The combination of metal nanoparticles such as copper, silver and other active ingredients promotes the antiviral and antibacterial action ${ }^{57}$. They have also developed an ergonomically designed 3D-printed ear guard that holds the face mask strap in a place without any pressure to the wearer's ear. Long-time usage of strapped and tight-fitting face masks can be painful, and a cause of concern for HCWs.

Researchers at the Hong Kong University of Science and Technology have developed a coating which could drastically reduce coronavirus transmission rates. The spray-on coating contains millions of nano-capsules containing disinfectants that are effective in killing bacteria, viruses and spores, even after the spray has dried. Unlike common disinfectants such as bleach or alcohol, these nano-capsules are heat-sensitive particles that activate and kill viruses upon human contact. They are also nontoxic, and skin- and environment-friendly. Recently, they have been approved for manufacture and use for domestic $\operatorname{purposes}^{58}$.

Sonovia's ultrasonic fabric-finishing technology, invented by two researchers at the Bar-Ilan University, Israel, consists of mechanically infused antiviral as well as antimicrobial zinc and copper-oxide nanoparticles into textiles for application as facemasks and other PPE. The finished textile has been shown to be effective against some strains of influenza as well as six strains of bacteria, including E. coli and Staphylococcus. The effectiveness was found to last for up to 100 washes at $75^{\circ} \mathrm{C}$ $\left(167^{\circ} \mathrm{F}\right)$, or 65 washes at $92^{\circ} \mathrm{C}\left(197^{\circ} \mathrm{F}\right)$. The effectiveness of these textile finishes against SARS-CoV-2 has not been established yet. Jerusalem-based Argaman Technologies has developed a washable, breathable and antiviral layered facemask named Bio-Block. This mask is made from proprietary cotton embedded with accelerated 
copper-oxide particle fibres called CottonX and a nanofibre textile which blocks viruses. The nanofibre has small pores that prevent the entry of pathogens, while the CottonX fibres destroy any pathogens that come in contact with the mask. The mask is effective against bacteria like Staphylococcus and E. coli for 50 industrial washings or 100 home washings. A hospital test conducted earlier found that CottonX bedding and gowns in a hospital ICU could reduce multidrug-resistant pathogens by about $50 \%$. However, like the Sonovia textile, these masks have not yet been tested against SARS-CoV-2 (ref. 59).

\section{Potential antiviral coatings from the literature}

van Doremalen et al. $^{3}$ studied the viability of SARSCoV-2 on various surfaces like plastic, stainless steel, copper, cardboard as well as aerosol. The longest viability was found to be on plastics and stainless-steel surfaces with the estimated median virus half-life of approximately 8.6 and $5.6 \mathrm{~h}$ respectively. On the other hand, copper was found to be effective in inactivating the virus within a short period of time. Earlier findings also report the effectiveness of brass containing at least $70 \%$ copper to be highly effective against the CoV-229E virus, due to copper ion release and the generation of reactive oxygen species $^{60}$. Nanoparticles of copper salts and/or solutions (chloride, iodide, sulphide, etc.) have also showed proven antiviral effect ${ }^{61-63}$. Copper-oxide nanoparticles have proven antiviral efficacy against influenza virus. They are known to show low toxicity as well when exposed to eukaryotic cells ${ }^{64,65}$. Nanoparticles of silver inhibit viral reproduction; however, their viricidal activity depends on the target virus ${ }^{66}$. Similarly, gold nanoparticles (AuNPs) when blended with polymers or coated with sulphated ligands, also bind to the envelope glycoprotein of the virus $^{67}$. Incorporating these metal ions on the surfaces of PPE like shoe covers, surgical gowns, hair covers, respirators, etc. can help prevent further viral transmissions.

Bright et al. ${ }^{68}$ studied the antiviral properties of zeolite (sodium aluminosilicate) powders amended with metal ions using various types of viruses, including human coronavirus 229E. Metal ions may reside within the pores of zeolites thereby acting as ion exchangers, and help in exchanging metal ions for other cations in the environment. These authors described the antiviral effect of zeolite powders modified with silver, copper and zinc ions in phosphate-buffered saline against human coronavirus 229E (ref. 68). Additionally, they also studied the survival of viruses on surfaces of plastics that have been incorporated with zeolite containing $\mathrm{Ag}$ and $\mathrm{Cu}$ ions. They found that zeolites containing silver ions showed significant virucidal effect, while a combination of silver/copper ions yielded a $>5.13 \log 10$ reduction within $24 \mathrm{~h}$. On plastic surfaces incorporated with a combination of zeolites with silver/copper ions, $>1.7 \log 10$ reduction was achieved for coronavirus 229E. Viruses that contain sulphhydryl termini generally bind to silver, interfering with viral replication $^{69}$. Moreover, silver may also modify the adsorption of viruses to host cells by inactivating the nucleic acid within the viral capsid ${ }^{70}$. Copper was also considered to be toxic, possibly due to the blocking of functional groups on virus proteins and the inactivation of their enzymes. The zeolites containing metal ions could be researched for SARS-CoV-2 due to their virucidal effect against enveloped viruses. Zeolites can be incorporated as plastic-based coatings or directly incorporated into the PPE fibres. Polymer nanocomposites with metals are known to be extremely effective in controlling and providing long-lasting release of ions for disinfection ${ }^{71,72}$.

Graphene is considered to be a potential antimicrobial nanomaterial due to its large surface area, high carrier mobility and its biocompatibility. Chen et al. ${ }^{73}$ studied the antiviral activity of graphene oxide (GO) sheets and GO sheets modified with silver particles (GO-Ag) against enveloped feline coronavirus (FCoV). They reported a $16 \%$ and $25 \%$ inhibition of $\mathrm{FCoV}$ by bare GO sheet and GO-Ag respectively. They suggested the application of GO and GO-Ag for coatings on PPE to decrease the transmission of viruses. Figure 3 illustrates the mechanism of antiviral action of $\mathrm{GO}$ and $\mathrm{GO}-\mathrm{Ag}$.

Ye et $a l .{ }^{74}$ showed promising antival activity of GO sheets against enveloped viruses like pseudorabies virus (PRV; a DNA virus) and porcine epidemic diarrhoea virus (PEDV; an RNA virus). They achieved about $2 \log$ reduction in both types of viruses at non-cytotoxic concentrations. They attributed the antiviral activity of GO and reduced $\mathrm{GO}(\mathrm{rGO})$ to their unique single-layer structure as well as negative charge. They observed that both GO and rGO showed similar antiviral activity, indicating that the oxygen-containing groups in them are not essential for the antiviral activity. They further modified GO with a non-ionic polymer and polydiallyldimethylammonium chloride (PDDA), a cationic polymer. The cationic

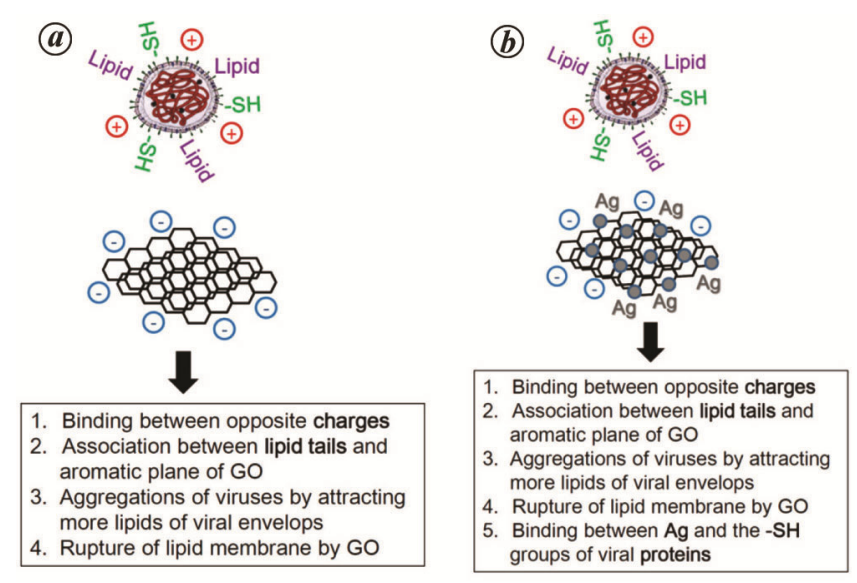

Figure 3. Schematic of antiviral mechanism of (a) graphene oxide (GO) and (b) GO-Ag. (Reprinted with permission from Palza et al..$^{71}$. Copyright 2016 Multidisciplinary Digital Publishing Institute.) 


\section{REVIEW ARTICLES}

GO-PDDA showed no antiviral activity while the nonionic graphene oxide-polyvinylpyrrolidinone (GO-PVP) retained the same antiviral activity as bare GO, suggesting that the negative charge on GO is required for the antiviral mechanism of GO and rGO. Also, they found that single GO exhibited superior antiviral activity compared to multilayered graphite and graphite oxide, suggesting that their nanosheet structure is important for antiviral properties. Furthermore, GO inactivated the viruses by structural destruction prior to viral entry. Bhattacharjee et $a l .{ }^{75}$ reported the efficacy of GO modified with metal nanoparticles for modification of PPE surfaces. Various reports of graphene derivatives modified with metals like $\mathrm{Ag}, \mathrm{Fe}, \mathrm{Cu}, \mathrm{Zn}$, etc. have also been reported to show strong antiviral performance against both enveloped as well as non-enveloped viruses ${ }^{76,77}$. Figure 4 depicts the various mechanisms responsible for antiviral effect of GO.

Eoczechin et al. ${ }^{78}$ studied the antiviral activity of seven different carbon quantum dots (CQDs) for the treatment of human coronavirus $\mathrm{HCoV}-229 \mathrm{E}$ infections. The CQDs were derived from hydrothermal carbonization of ethylenediamine/citric acid as carbon precursors, and they were further modified with boronic acid ligands. The CDQs exhibited promising virucidal effect. The underlying mechanism of action of these CQDs was suggested to be the interaction of the functional groups of CQDs with HCoV-229E entry receptors. Further, they also exhibited an equally large virus inhibition activity at the viral replication step. Du et $a l^{79}$ developed glutathione capped$\mathrm{Ag}_{2} \mathrm{~S}$ nanoclusters which proved to be efficient in suppressing porcine epidemic diarrhoea (PEDV), a model coronavirus activity by three orders of magnitude at a noncytotoxic concentration within $12 \mathrm{~h}$. Figure 5 shows that the nanoclusters inhibit the synthesis of negativestrand viral RNA and viral budding.

Recently, traditional Chinese medicine is gaining attention for the development of antiviral agents. Ting et al. ${ }^{80}$

(a)

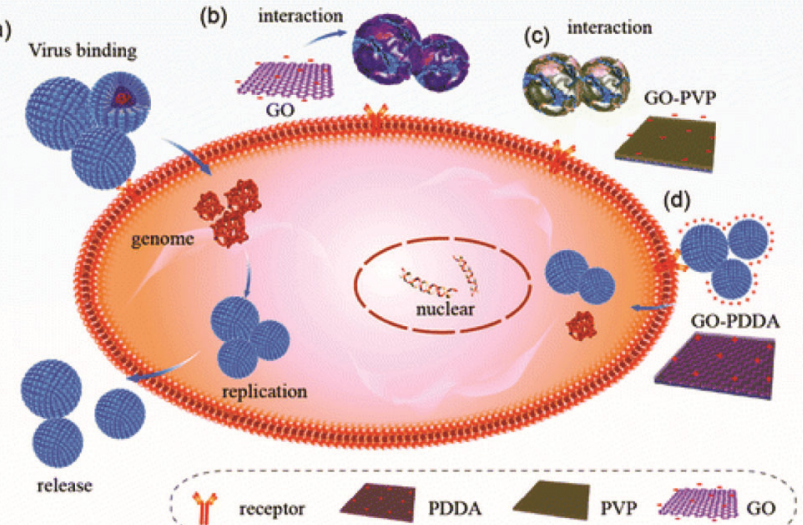

Figure 4. Possible mechanisms of the antiviral activity of GO. (Reprinted with permission from Ye et $a l^{74}$. Copyright 2015 American Chemical Society.) used curcumin to develop uniform and stable cationic carbon dots (CCM-CDs) with antiviral properties. The efficacy of the CCM-CDs was tested against PEDV, and it was found that they inhibit the proliferation of PEDV more efficiently than non-curcumin modified carbon dots. They change the viral surface protein structure, thereby inhibiting the viral entry. CCM-CDs also exhibit the viral inhibition mechanisms of $\mathrm{Ag}_{2} \mathrm{~S}$ nanoclusters. Tong et $a l{ }^{81}$ developed highly biocompatible carbon quantum dots using glycyrrhizic acid (Gly-CDs), which is again an active ingredient of Chinese herbal medicine, employing a hydrothermal method. These also showed promising antiviral effect against PEDV.

Single-walled carbon nanotubes (SWCNTs) have been used as antiviral drug carriers like isoprinosine and ribavirin, since miniscule nanoparticles $(<10 \mathrm{~nm})$ can migrate through cell membranes and inhibit post-attachment virus replication $^{82}$. Nanoparticles can be modified with antiviral drugs and can be incorporated in the PPE. World Health Organization approved drugs like chloroquine (CQ) and hydroxychloroquine (HCQ) have the ability to act in the first step of the viral lifecycle. CQ and HCQ are aminoquinolines, a class of heterocyclic scaffolds having an amino group with the ability to bind and form complexes with metals like $\mathrm{Fe}(\mathrm{II}), \mathrm{Ni}(\mathrm{II}), \mathrm{Zn}(\mathrm{II})$ and $\mathrm{Cu}(\mathrm{II})$ ions ${ }^{83}$. Moreover, the metal complexes of 8-hydroxyquinoline have already shown proven antiviral efficacy ${ }^{84}$. Other antiviral drugs/nanoparticle combinations can be possibly studied as well.

Nagle et $a l^{85}$ studied the antiviral potential of sulphated polysaccharides (carrageenan) against several enveloped and non-enveloped viruses, including SARSCoV-2. They reported that sulphated polysaccharides from Porphyridium, aunicellular microalgae, act by inhibiting the binding and internalization of the virus into the host cells. Porphyridium is a red microalgae that can be cultivated round the year in open and close cultivation

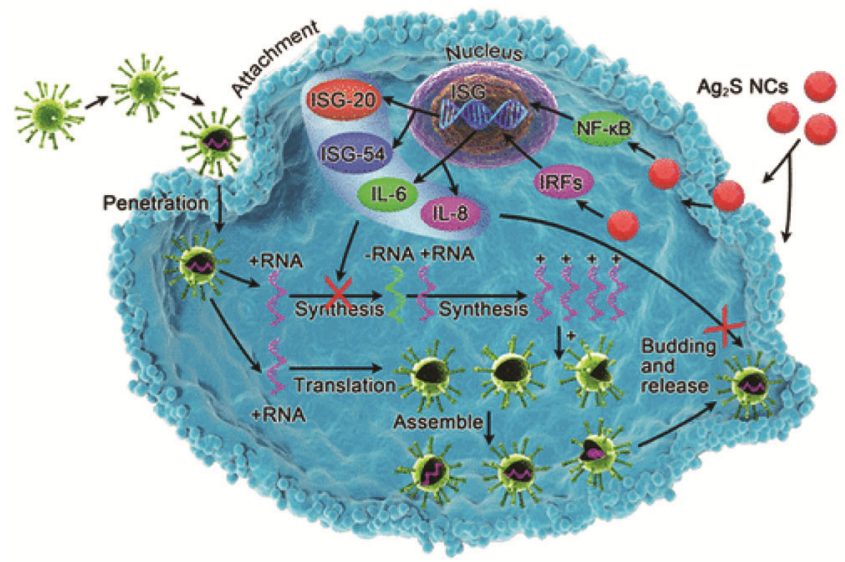

Figure 5. Potential mechanism for the antiviral activity of $\mathrm{Ag}_{2} \mathrm{~S}$ nanoclusters. (Reprinted with permission from Ye et al. ${ }^{74}$. Copyright 2018 American Chemical Society.) 
systems. The sulphated polysaccharides dissolves in the growth medium causing the formation of exopolysaccharides, which are complex sugar molecules mainly consisting of xylose $(38 \%)$, glucose $(24 \%)$, galactose $(22 \%)$ and glucuronic acid (10\%). Arabinose, rhamnose and mannose are also found in minor concentrations. They are biocompatible and easily biodegradable, and also play an important role in medicine, cosmetics and food.

Quan et $a l .{ }^{86}$ reported the deactivation of viruses from surgical masks by functionalization of the main fibrous filtration unit of the mask with sodium chloride $(\mathrm{NaCl})$ salt. They claimed that the salt coating on the surface dissolves upon exposure to virus aerosols and recrystallizes during the drying process, killing the pathogens. When tested after tightly sealing the sides of the masks, saltcoated filters showed remarkably higher filtration efficiency than conventional mask filtration layer. They obtained a $100 \%$ survival rate in mice exposed to H1N1 and $\mathrm{H} 5 \mathrm{~N} 1$ virus. Also, the captured viruses on the saltcoated filters underwent rapid loss in their efficiency when compared to gradual decrease in their activity when bare filters were used. This strategy could be used against all influenza virus subtypes, including SARS-CoV-2. Rocky et $a l{ }^{87}$ reported a simple way to improve the virus screening efficiency of homemade cotton or linen woven fabric-based face-masks using a salt-starch treatment. The starch in this case increases the efficiency of pathogenic droplet absorption by the fabric.

Although some free fatty acids derived from milk and vegetable oil are known to possess antiviral properties, the therapeutic applications of these short-to-mediumchain fatty acids are limited by physical characteristics such as immiscibility in aqueous solution ${ }^{88}$. Fletcher et $a l .{ }^{89}$ studied the virucidal efficiency of an emulsion based on short chain caprylic acid (ViroSAL) on enveloped viruses. They found that ViroSAL was effective against a range of enveloped viruses, including SARS-CoV-1 in a concentration- and time-dependent manner. Its inability to inhibit non-enveloped viruses suggests that its mechanism of action may be via surfactant disruption of the viral envelope. They suggested the topical application of these emulsions. The ability of ViroSAL to inhibit SARS-CoV1 suggests that it could be effectively used against SARS-CoV-2.

There are various reports indicating the use of quaternary ammonium containing compounds as antiviral treatments for many viruses, including coronaviruses. These molecules act by deactivating the protective lipid coating of the enveloped viruses like SARS-CoV-2. Although the disinfection time depends on the compound concentration and contact times, most of the quaternary ammonium compounds can deactivate the virus in just a few minutes. One such quaternary ammonium compound listed by FDA as generally regarded as safe (GRAS) is cetylpyridinium chloride. It is used widely in personal care like mouthwash and also as an antimicrobial agent for meat and poultry products (up to 1\%). Cetylpyridinium chloride likely promotes enveloped-virus inactivation by destroying the capsid as well as through its lysosomotropic action, which is common for quaternary ammonium compounds. Another similar compound under study is miramistin, a drug belonging to the group of cationic antiseptics, which is also a quaternary ammonium compound reported to have a wide array of biological activities, including antiviral against $\mathrm{HIV}^{90}$. Sportelli et $a l .^{91}$ achieved synergistic antimicrobial performance by combining a copper core and a quaternary ammonium shell, both of which are capable of strong antiviral action.

Kandeel et $a l .{ }^{92}$ studied the virucidal activity of three types of polyanionic dendrimers consisting of the terminal groups sodium carboxylate (generations 1.5, 2.5, 3.5 and 4.5), hydroxyl (generations 2, 3, 4 and 5), and succinamic acid (generations 2, 3, 4 and 5) against the enveloped MERS-CoV. The most potent inhibition of MERS-CoV plaque formation was reported for the 1.5th generation sodium carboxylate functionalized dendrimer with a $40.5 \%$ inhibition of virus.

Milewska et al. ${ }^{93,94}$ obtained cationically modified chitosan, $N$-(2-hydroxypropyl)-3-trimethylammonium chitosan chloride (HTCC) by the reaction of chitosan with glycidyltrimethylammonium chloride (GTMAC). They prepared HTCC with different degrees of substitution were obtained. They showed that HTCC inhibits the interaction of a coronavirus with its receptor, thereby blocking its entry into a cell. Ciejka et al. ${ }^{95}$ developed a novel nano/microsphere which was capable of adsorbing coronaviruses. The biopolymer was obtained by crosslinking of chitosan with genipin, a plant-based nontoxic compound followed by reaction with glycidyltrimethylammonium chloride (GTMAC). The obtained nano/ microsphere was effective in adsorbing human coronavirus NL63 (HCoV-NL63), mouse hepatitis virus (MHV) and human coronavirus $\mathrm{HCoV}-\mathrm{OC} 43$ particles in aqueous virus suspensions. They also showed that HCoV-NL63 particles could be desorbed from the nano/microsphere surface having a salt solution of high ionic strength with retention of virus virulence. These could be studied for the adsorption of coronaviruses from PPE. Ren et al. ${ }^{96}$ coated 1-chloro-2,2,5,5-tetramethyl-4-imidazolidinone, a type of $N$-halamine on non-woven fabrics as an effective antiviral agent against avian influenza virus (H5N1 virus). Higher concentrations of the compound were found to completely inactivate the virus by disrupting its RNA. Moreover, they confirmed that active chlorine in the compound was stable, and that the coating was not volatile and did not release any gaseous chlorine.

There are various reports of using polymers functionalized with acid functionalities like carboxylic acid, a phosphonic acid, a hydrosulphonic acid, a boronic acid or a conjugate base as potential antiviral agents. The functional groups are either directly linked to the polymer backbone or attached via an aliphatic spacer group. The 


\section{REVIEW ARTICLES}

acidic groups are either deprotonated carrying a negative charge or they may be in the form of a conjugate base whereby the negative charge of the polymer will be balanced either by a suitable counter cation such as alkali metal ions like sodium/potassium/caesium ions or by alkaline earth metal ions like magnesium ions or by tetraalkylammonium ions ${ }^{97}$. Proanthocyanidin polymers synthesized either chemically or isolated from a croton or a calophyllum show significant antiviral activity ${ }^{98}$. Phthalocyanine derivatives can be blended in an organic or inorganic carrier, and be coated or incorporated into textile fibres to develop antiviral $\mathrm{PPE}^{99}$.

Si et al. ${ }^{100}$ reported the development of green bioprotective nanofibrous membranes (RNMs) with rechargeable antimicrobial properties that can effectively produce biocidal reactive oxygen species (ROS) solely driven by daylight (Figure 6). They state that the photoactive RNMs can store biocidal activity under light irradiation and can readily release ROS under dim light or dark conditions, thus making their biocidal function 'always online'. The ROS-producing moieties used were benzophenones and polyphenol derivatives, which are popular as photosensitizers. They developed tunable pore-size nanofibrous membranes from poly (vinyl alcohol-co-ethylene; PVA-co-PE) by electrospinning to immobilize the photosensitizer moieties. They propose to use these RNMs as a scalable biocidal layer for PPE, that providing contact killing against viruses and bacteria either in aerosol or liquid form. RMNs may be particularly studied for enveloped viruses like SARS-CoV-2, since the ROS produced can easily cause cross-linking of the virus capsid proteins, resulting in direct impairment of the capability to bind to the host surface.
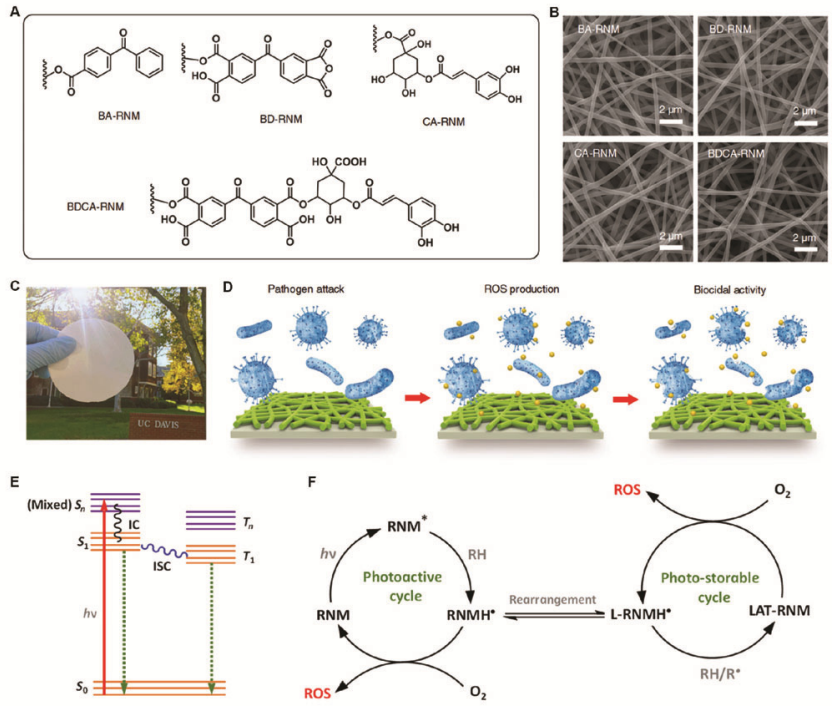

Figure 6. Design, structure and biocidal function of rechargeable antibacterial and antiviral nanofibrous membranes. (Reprinted with permission from Si et al. ${ }^{100}$. Copyright 2018 American Association for the Advancement of Science.)
Although currently the surgical-grade N95 mask provides the highest level of protection, its filtration efficiency for particles $<300 \mathrm{~nm}$ (which is the typical size of the SARS-CoV-2 particles $-65-125 \mathrm{~nm}$ ) is only around $85 \%$ due to its larger pore size. Also, the masks are not reusable. To overcome this issue El-Atab et al. ${ }^{101}$ developed a replaceable filtration membrane which can be attached to the N-95 masks. As shown in Figure 7, they developed a flexible nano-porous template based on a commercial silicon-on-insulator wafer using $\mathrm{KOH}$ etching. This template was then used as a hard mask during the reactive ion etching process which enables the transfer of pattern onto a flexible and lightweight polyimide (PI) membrane. The membranes had a pore size of about $5 \mathrm{~nm}$ with an airflow rate above $85 \mathrm{l} / \mathrm{min}$, which confirmed breathability. Moreover, these authors claim the membrane to be intrinsically hydrophobic, thus providing antifouling and self-cleaning properties ${ }^{101}$.

\section{Summary}

This article comprehensively presents the need for PPE by elaborating on the different mechanisms of infection transfer in healthcare set-ups - clearly highlighting the need for PPE to prevent such transmission and also secondary infections. The PPE are designed in such a way that they form a barrier in the transmission pathways of pathogens. Recent additions to PPE include antimicrobial coatings or measures to combat pathogens from penetrating them, and the use of alternate materials and processes to prevent particle release in more sensitive environments. There is a thrust which drives the market towards

(a)

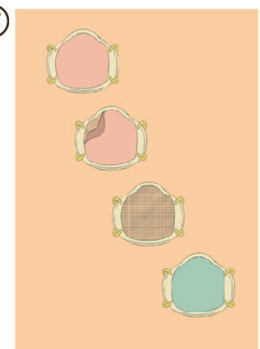

(b)

(c)
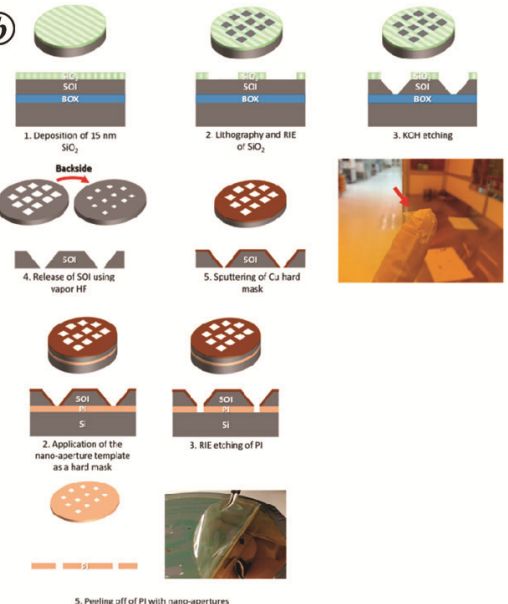

Figure 7. $\boldsymbol{a}$, Schematic depicting the use of the developed replaceable membrane on a reusable N95 mask after folding it. $\boldsymbol{b}$, Fabrication process of the Si-based template. $c$, Fabrication process of the final flexible hydrophobic polyimide thin film membrane. (Reprinted with permission from El-Atab et al. ${ }^{101}$. Copyright 2020 American Chemical Society.) 
the use of disposable rather than reusable PPE, to enhance the sale of new products. This also means that the research in PPE is also driven towards the development of disposable products with special focus on antimicrobial performance, making them sturdy for longer duration. This is accomplished by the use of functional antiviral finishes which may be nanoparticles (like copper, silver and zinc), biocidal polymers, sprayable coatings and specialized processing techniques. Also there are several candidates available in the literature, which can become potential antiviral/antimicrobial coatings with diverse performance ranging from 2 to 7 log reduction. A few of them include metal and metal-salt nanoparticles, carbonaceous materials like carbon nanotubes, graphene and its modifications, graphene, quantum dots and nanofibrous membranes. Through this article it is expected that the research in PPE for the next few years will be focused on the incorporation of smart materials, besides antiviral properties.

Conflict of interest: The authors declare no conflict of interest.

1. Khedkar, P. H. and Patzak, A., SARS-CoV-2: what do we know so far? Acta Physiol., 2020, e13470; doi:10.1111/apha. 13470 .

2. FDA, Personal protective equipment for infection control. Available at: https:/www.fda.gov/medical-devices/general-hospital-devices-and-supplies/personal-protective-equipment-infection-control (accessed on 15 May 2020).

3. van Doremalen, N. et al., Aerosol and surface stability of SARSCoV-2 as compared with SARS-CoV-1. New Eng. J. Med., 2020, 382, 1564-1567.

4. Casanova, L., Rutala, W. A., Weber, D. J. and Sobsey, M. D., Coronavirus survival on healthcare personal protective equipment. Infect. Control Hosp. Epidemiol., 2010, 31, 560-561.

5. Smith, J. S. et al., Effect of various decontamination procedures on disposable N95 mask integrity and SARS-CoV-2 infectivity. medRxiv, 2020; 2020.04.11.20062331. doi:10.1101/2020.04.11. 20062331.

6. Sportelli, M. C. et al., Can nanotechnology and materials science help the fight against SARS-CoV-2? Nanomaterials, 2020, 10, 802.

7. Fishman, N. and Calfee, D. P., Prevention and Control of Health Care-Associated Infections. Goldman's Cecil Medicine: Twenty Fourth Edition, Elsevier Inc., 2011, 2.

8. Otaiza, F., Orsini, M. and Pohlenz, M., Prevention and control of healthcare associated infections. Basic Recommendations, 2018.

9. Respiratory protection | Fact sheets | Publications and products | TB | CDC. Available at: https://www.cdc.gov/tb/publications/ factsheets/prevention/rphcs.htm (accessed on 15 May 2020).

10. Belkin, N. L., The evolution of the surgical mask: filtering efficiency versus effectiveness. Infect. Control Hosp. Epidemiol., 1997, 18, 49-57.

11. Madsen, P. O. and Madsen, R. E., A study of disposable surgical masks. Am. J. Surg., 1967, 114, 431-435.

12. How surgical masks are made, tested and used. Available at: https://www.thomasnet.com/articles/other/how-surgical-masks-aremade/ (accessed on 17 May 2020).

13. Smith, J. D. et al., Effectiveness of N95 respirators versus surgical masks in protecting health care workers from acute respiratory infection: a systematic review and meta-analysis. Can. Med. Assoc. J., 2016, 188, 567-574.

14. Surgical face masks in modern operating rooms - a costly and unnecessary ritual? J. Hosp. Infect., 1991, 18, 239-242.

15. Brosseau, L., Ann, R. B. and ScD. Blogs | CDC, N95 respirators and surgical masks. Available at: https://blogs.cdc.gov/nioshscience-blog/2009/10/14/n95/ (accessed on 18 May 2020).

16. CDC, NIOSH and NPPTL. Infographic-understanding the difference, Surgical mask, N95 respirator.

17. Surgical masks, respirators, barrier masks: which masks actually protect against coronavirus? MedicalExpo e-Magazine. Available at: http://emag.medicalexpo.com/which-masks-actually-protectagainst-coronavirus/ (accessed on 16 May 2020).

18. Respirators - Respirators versus surgical masks: OSH answers. Available at: https://www.ccohs.ca/oshanswers/prevention/ppe/ surgical_mask.html (accessed on 16 May 2020).

19. Sterile vs non-sterile gloves. Available at: https:/glovenation. com/blogs/default-blog/sterile-vs-non-sterile-gloves (accessed on 25 May 2020).

20. Quill.com, Exam gloves vs surgical gloves: what's the difference? Available at: https://www.quill.com/content/index/resource-center/ healthcare/exam-surgical-gloves/default.cshtml (accessed on 25 May 2020).

21. USA Medical and Surgical Supplies, 8 Things to consider when buying surgical gloves. Available at: https://www.usamedicalsurgical.com/blog/8-things-to-consider-when-buying-surgicalgloves/ (accessed on 25 May 2020).

22. Lathan, S. R., Caroline Hampton Halsted: the first to use rubber gloves in the operating room. Baylor Univ. Med. Cent. Proc., 2010, 23, 389-392.

23. Biotechnology Innovation, Latex Gloves. Available at: http:// biotechnology-innovation.com.au/innovations/instruments/latex gloves.html (accessed on 23 May 2020).

24. FDA proposes ban of powdered medical gloves. Available at: https://www.medscape.com/viewarticle/860722?nlid=102645 3901\&src=wnl_newsalrt_160321_MSCPEDIT\&uac=28013DZ\&im$\mathrm{pID}=103137 \overline{9} \& \mathrm{faf}=1$ (accessed on 23 May 2020).

25. FDA bans most powdered gloves. Available at: https://www. ada.org/en/publications/ada-news/2016-archive/december/fda-bansmost-powdered-gloves (accessed on 23 May 2020).

26. Hourglass International, Inc. Powder-free exam glove choices chlorinated vs polymer-coated. Available at: https:/hourglassintl.com/2015/05/18/powder-free-exam-glove-choices-chlorinatedvs-polymer-coated/ (accessed on 23 May 2020).

27. GW, G., 'Hand in glove': a centennial observation on the surgical use of rubber gloves. South. Med. J., 1991, 84, 1012-1017.

28. Ellis, H., Evolution of the surgical glove. J. Am. Coll. Surg., 2008, 207, 948-950.

29. Serrano, C. W., Wright, J. W. and Newton, E. R., Surgical glove perforation in obstetrics. Obstet. Gynecol., 1991, 77, 525-528.

30. Karkera, P., Pinto, A., Ramchandra, M., Thakur, A. and D'Souza, F., Unnoticed glove perforation during surgery: single gloves versus double gloves. Saudi Surg. J., 2014, 2, 47.

31. AvaCare Medical. Disposable gloves guide. Nitrile vs latex vs Vinyl. Available at: https://avacaremedical.com/medical-glovesguide (accessed on 24 May 2020).

32. B4 Brands. Latex vs nitrile vs vinyl Gloves...which to choose? Available at: https://b4brands.com/blog/latex-vs-nitrile-vs-vinylgloves-which-to-choose/ (accessed on 24 May 2020).

33. Westlab. Nitrile vs latex vs vinyl gloves. Available at: https:/www.westlab.com/blog/2017/08/17/nitrile-vs-latex-vs-vinylgloves (accessed on 24 May 2020).

34. Heese, A., Hintzenstern, J. V., Peters, K. P., Koch, H. U. and Hornstein, O. P., Allergic and irritant reactions to rubber gloves in medical health services: spectrum, diagnostic approach, and therapy. J. Am. Acad. Dermatol., 1991, 25, 831-839.

35. Taylor, P., Chemical Allergy Masquerade. 


\section{REVIEW ARTICLES}

36. Tanner, J. and Parkinson, H., Double gloving to reduce surgical cross-infection. Cochrane Database Syst. Rev., 2009; doi:10.1002/ 14651858.CD003087.pub2

37. Mischke, C., Verbeek, J. H., Saarto, A., Lavoie, M. C., Pahwa, M. and Ijaz, S., Gloves, extra gloves or special types of gloves for preventing percutaneous exposure injuries in healthcare personnel. Cochrane Database Syst. Rev., 2014, 3, CD009573; doi: 10.1002/14651858.CD009573.pub2. PMID: 24610769.

38. Korniewicz, D. M., Advantages and disadvantages of non-latex surgical gloves advantages and disadvantages of non-latex surgical gloves. Business Briefing: Global Surgery, 2005.

39. Lovitt, S. A., Nichols, R. L., Smith, J. W., Muzik, A. C. and Pearce, P. F., Isolation gowns: a false sense of security? Am. J. Infect. Control, 1992, 20, 185-191.

40. FDA, Medical gowns. FDA. Available at: https://www.fda.gov/ medical-devices/personal-protective-equipment-infection-control/ medical-gowns (accessed on 26 May 2020).

41. Leonas, K. K., Transmission of small particles through selected surgical gown fabrics. In Proceedings of the Largest International Nonwovens Technical Conference, Assoc Nonwoven Fabrics Ind, 1998; doi:10.1177/1558925099os-800116.

42. Siegel, J. D., Rhinehart, E., Jackson, M. and Chiarello, L., Guideline for isolation precautions: preventing transmission of infectious agents in health care settings. Am. J. Infect. Control, 2007, 35(Suppl. 2), S65-S164.

43. Neely, A. N. and Maley, M. P., A survey of Gram-negative bacteria survival on hospital fabrics and plastics. J. Burn Care Rehabil., 2000, 21, 523-527.

44. Hatch, K. L., Textile Science, West Publishing Co, MN, USA, 1993.

45. Li, Y. and Wang, Z., Mathematical simulation of dynamic coupled heat and liquid moisture transfer in multilayer anisotropic porous polymers. J. Appl. Polym. Sci., 2004, 94, 1590-1605.

46. Laufman, H., Eudy, W. W., Vandernoot, A. M., Harris, C. A. and Liu, D., Strike through of moist contamination by woven and nonwoven surgical materials. Ann. Surg., 1975, 181, 857-862.

47. Moylan, J. A., Fitzpatrick, K. T. and Davenport, K. E., Reducing wound infections: improved gown and drape barrier performance. Arch. Surg., 1987, 122, 152-157.

48. Selection and use of protective apparel and surgical drapes in healthcare facilities, 2005.

49. DiGiacomo, J. C., Odom, J. W., Ritota, P. C. and Swan, K. G., Cost containment in the operating room: use of reusable versus disposable clothing - PubMed. Am. Surg., 1992, 58, 654656.

50. Global surgical gown market is expected to grow with a CAGR of $4.6 \%$ over the forecast period from 2018-2024. Available at: https://www.prnewswire.com/news-releases/global-surgical-gownmarket-is-expected-to-grow-with-a-cagr-of-4-6-over-the-forecastperiod-from-2018-2024--301006056.html (accessed on 28 May 2020).

51. Dais announces plans to use its patented aqualyte advanced nanomaterial to immobilize a wide range of bacteria and viruses, including coronaviruses. Available at: https://apnews.com/ NewMediaWire/150cb55908534590a12c0b6da8603d58 (accessed on 30 May 2020).

52. HeiQ, Textile treatment effective against corona virus. Available at: https://www.techtextrends.com/news/chemicals-and-textileauxiliaries/HeiQ-Textile-treatment-effective-against-coronavirus20295 (accessed on 22 May 2020).

53. Devan offers antiviral solutions for textiles-Fibre2Fashion. Available at: https:/www.fibre2fashion.com/news/textile-news/ devan-offers-antiviral-solutions-for-textiles-266052-newsdetails.htm (accessed on 22 May 2020).

54. OEM Update. Preventing the spread of COVID-19 through touch with anti-viral surface coating. Available at: https://www. oemupdate.com/case-study/preventing-the-spread-of-covid-19- through-touch-with-anti-viral-surface-coating/ (accessed on 30 May 2020).

55. Technical overview | Anti-viral and anti-bacterial technology Cufitec $^{\circledR} \mid$ Product and service $\mid$ NBC Meshtec Inc. The most advanced mesh technology in the world. Available at: http://www. nbc-jp.com/eng/product/cufitec/technology.html\#resin (accessed on 22 May 2020).

56. New antiviral textile finish could reduce the spread of disease. Sourcing Journal. Available at: https://sourcingjournal.com/ topics/raw-materials/new-antiviral-textile-finish-reduce-spreaddisease-7237/ (accessed on 22 May 2020).

57. IIT Guwahati researchers develop affordable antimicrobial spraybased coating for PPE. The Economic Times. Available at: https:// economictimes.indiatimes.com/news/science/iit-guwahati-researchers-develop-affordable-antimicrobial-spray-based-coating-forppe/articleshow/75119890.cms (accessed on 22 May 2020).

58. $£ 7$ antiviral spray that could 'protect surfaces from coronavirus for 90 days' goes on sale in Hong Kong. The Sun. Available at: https:/www.thesun.co.uk/news/11495167/antiviral-spray-protectsurfaces-from-coronavirus-90-days-on-sale/ (accessed on 22 May 2020).

59. ISRAEL21c. New antiviral masks from Israel may help stop deadly coronavirus. Available at: https://www.israel21c.org/newantiviral-masks-from-israel-may-help-stop-deadly-virus/ (accessed on 22 May 2020).

60. Warnes, S. L., Little, Z. R. and Keevil, C. W., Human coronavirus $229 \mathrm{E}$ remains infectious on common touch surface materials. MBio, 2015, 6.

61. Khodashenas, B. and Ghorbani, H. R., Synthesis of copper nanoparticles: An overview of the various methods. Korean J. Chem. Eng., 2014, 31, 1105-1109.

62. Fujimori, Y. et al., Novel antiviral characteristics of nanosized copper(i) iodide particles showing inactivation activity against 2009 pandemic H1N1 influenza virus. Appl. Environ. Microbiol., 2012, 78, 951-955.

63. Sucipto, T. H. et al., Antiviral activity of copper(II) chloride dihydrate against dengue virus type-2 in vero cell. Indones. $J$. Trop. Infect. Dis., 2017, 6, 84.

64. Iyigundogdu, Z. U., Demir, O., Asutay, A. B. and Sahin, F., Developing novel antimicrobial and antiviral textile products. Appl. Biochem. Biotechnol., 2017, 181, 1155-1166.

65. Shaligram, S. and Campbell, A., Toxicity of copper salts is dependent on solubility profile and cell type tested. Toxicol. Vitr., 2013, 27, 844-851.

66. Kerry, R. G. et al., Nano-based approach to combat emerging viral (NIPAH virus) infection. Nanomed.: Nanotechnol. Biol. Med., 2019, 18, 196-220.

67. Di Gianvincenzo, P. et al., Gold nanoparticles capped with sulfate-ended ligands as anti-HIV agents. Bioorg. Med. Chem. Lett., 2010, 20, 2718-2721.

68. Bright, K. R., Sicairos-Ruelas, E. E., Gundy, P. M. and Gerba, C. P., Assessment of the antiviral properties of zeolites containing metal ions. Food Environ. Virol., 2009, 1, 37-41.

69. Davies, R. L. and Etris, S. F., The development and functions of silver in water purification and disease control. Catal. Today, 1997, 36, 107-114.

70. Thurman, R. B. and Gerba, C. P., The molecular mechanisms of copper and silver ion disinfection of bacteria and viruses. Crit. Rev. Environ. Control, 1989, 18, 295-315.

71. Palza, H., Nuñez, M., Bastías, R. and Delgado, K., In situ antimicrobial behavior of materials with copper-based additives in a hospital environment. Int. J. Antimicrob. Agents, 2018, 51, 912917.

72. Cioffi, N. et al., Bioactive metal nanomaterials stabilized by bioactive agents and preparation process, 2010.

73. Chen, Y. N., Hsueh, Y. H., Hsieh, C. Te, Tzou, D. Y. and Chang, P. L., Antiviral activity of graphene-silver nanocomposites 
against non-enveloped and enveloped viruses. Int. J. Environ. Res. Public Health, 2016, 13; doi:10.3390/ijerph13040430.

74. Ye, S. et al., Antiviral activity of graphene oxide: how sharp edged structure and charge matter. ACS Appl. Mater. Interfaces, 2015, 7, 21578-21579.

75. Bhattacharjee, S., Joshi, R., Chughtai, A. A. and Macintyre, C. R., Graphene modified multifunctional personal protective clothing. Adv. Mater. Interfaces, 2019, 6, 1900622.

76. Perreault, F., De Faria, A. F., Nejati, S. and Elimelech, M., Antimicrobial properties of graphene oxide nanosheets: why size matters. ACS Nano, 2015, 9, 7226-7236.

77. Hang, X. et al., Antiviral activity of cuprous oxide nanoparticles against hepatitis C virus in vitro. J. Virol. Methods, 2015, 222, $150-157$.

78. Łoczechin, A. et al., Functional carbon quantum dots as medical countermeasures to human coronavirus. ACS Appl. Mater. Interfaces, 2019, 11, 42964-42974.

79. $\mathrm{Du}, \mathrm{T}$. et al., Glutathione-capped $\mathrm{Ag}_{2} \mathrm{~S}$ nanoclusters inhibit coronavirus proliferation through blockage of viral RNA synthesis and budding. ACS Appl. Mater. Interf., 2018, 10(5), 4369-4378; doi:10.1021/ACSAMI.7B13811

80. Ting, D. et al., Multisite inhibitors for enteric coronavirus: antiviral cationic carbon dots based on curcumin. ACS Appl. Nano Mater., 2018, 1, 5451-5459.

81. Tong, T. et al. Glycyrrhizic acid-based carbon dots with high antiviral activity by multisite inhibition mechanisms. Small, 2020, 16, 1906206.

82. Zhu, B., Liu, G. L., Ling, F. and Wang, G. X., Carbon nanotubebased nanocarrier loaded with ribavirin against grass carp reovirus. Antiviral Res., 2015, 118, 29-38.

83. Fanning, J. C. and Taylor, L. T., Some transition metal complexes of 8-aminoquinoline. J. Inorg. Nucl. Chem., 1965, 27, 2217-2223.

84. Phopin, K. et al., Antimalarial and antimicrobial activities of 8aminoquinoline-uracils metal complexes. EXCLI J., 2016, 15; doi:10.17179/excli2016-101.

85. Nagle, V., Gaikwad, M., Pawar, Y. and Dasgupta, S., Marine red alga Porphyridium sp. as a source of sulfated polysaccharides (SPs) for combating against COVID-19. Preprints, 2020.

86. Quan, F. S., Rubino, I., Lee, S. H., Koch, B. and Choi, H. J., Universal and reusable virus deactivation system for respiratory protection. Sci. Rep., 2017, 7, 1-10.

87. Rocky, M. M. H., Amzad, M., Bhuyan, H., Khan, R. and Akhtar, S., A simple homemade cloth mask for mass people in COVID19: salt-starching treatment on fabric for better bioaerosol filtration efficiency. 2020; doi:10.13140/RG.2.2.26003.91681

88. Thormar, H., Isaacs, C. E., Brown, H. R., Barshatzky, M. R. and Pessolano, T., Inactivation of enveloped viruses and killing of cells by fatty acids and monoglycerides. Antimicrob. Agents Chemother., 1987, 31, 27-31.

89. Fletcher, N. F. et al., A novel antiviral formulation inhibits a range of enveloped viruses. bioRxiv, 2020; 2020.03.29.009464. doi:10.1101/2020.03.29.009464

90. Ekins, S., Williams, A., Baker, N. and Tropsha, A., OSF. Repurposing quaternary ammonium compounds as potential treatments for COVID-19. Available at: https://osf.io/qfc6h/ (accessed on 22 May 2020).

91. Sportelli, M. C. et al., Electrochemical preparation of synergistic nanoantimicrobials. Molecules, 2020, 25; doi:10.3390/molecules25010049.

92. Kandeel, M., Al-Taher, A., Park, B. K., Kwon, H. and Al-Nazawi, M., A pilot study of the antiviral activity of anionic and cationic polyamidoamine dendrimers against the Middle East respiratory syndrome coronavirus. J. Med. Virol., 2020; jmv.25928. doi: $10.1002 / \mathrm{jmv} .25928$

93. Milewska, A. et al., Novel polymeric inhibitors of HCoV-NL63. Antiviral Res., 2013, 97, 112-121.

94. Milewska, A. et al., HTCC: Broad range inhibitor of coronavirus entry. PLOS ONE, 2016, 11.

95. Ciejka, J., Wolski, K., Nowakowska, M., Pyrc, K. and Szczubiałka, K., Biopolymeric nano/microspheres for selective and reversible adsorption of coronaviruses. Mater. Sci. Eng., 2017, C76, 735-742.

96. Ren, T., Dormitorio, T. V., Qiao, M., Huang, T. S. and Weese, J., N-halamine incorporated antimicrobial nonwoven fabrics for use against avian influenza virus. Vet. Microbiol., 2018, 218, 78-83.

97. Neenan, T. X., Harry Mandeville, W. and III, Antiviral polymers comprising acid functional groups and hydrophobic groups: Patent US6060235, PubChem. 2000.

98. Tempesta, M. S., Methods for using proanthocyandn polymers having antiviral activity. 1996.

99. Miki, M., Koichi, O. and Takakuwa Ryota, T., Antiviral agents, antiviral fibers and antiviral fiber structures. 2009.

100. Si, Y. et al., Daylight-driven rechargeable antibacterial and antiviral nanofibrous membranes for bioprotective applications. Sci. Adv., 2018, 4, eaar5931.

101. El-Atab, N., Qaiser, N., Badghaish, H. S., Shaikh, S. F. and Hussain, M. M., A flexible nanoporous template for the design and development of reusable anti-COVID-19 hydrophobic face masks. ACS Nano, 2020; acsnano.0c03976. doi:10.1021/ acsnano.0c03976

Received 23 December 2020; accepted 8 February 2021

doi: $10.18520 / \mathrm{cs} / \mathrm{v} 120 / \mathrm{i} 7 / 1169-1183$ 